Canadian

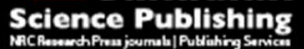

Canadian Journal of Civil Engineering Revue canadienne de génie civil

INFLUENCE OF GEOMETRIC AND MATERIAL CHARACTERISTICS ON THE BEHAVIOR OF REINFORCEDCONCRETE BEAM-COLUMN CONNECTIONS

\begin{tabular}{|r|l|}
\hline Journal: & Canadian Journal of Civil Engineering \\
\hline Manuscript ID & cjce-2016-0247.R2 \\
\hline Manuscript Type: & Article \\
\hline Date Submitted by the Author: & $25-J a n-2017$ \\
\hline Complete List of Authors: & $\begin{array}{l}\text { VANDANA, R; COLLEGE OF ENGINEERING, DEPARTMENT OF CIVIL } \\
\text { ENGINEERING } \\
\text { Bindhu, K.R; College of Engineering,Trivandrum }\end{array}$ \\
\hline Keyword: & $\begin{array}{l}\text { Cyclic loading, Seismic resistance, Ductility, Reinforced concrete moment } \\
\text { resisting frames, Beam column connection }\end{array}$ \\
\hline & \\
\hline
\end{tabular}




\section{INFLUENCE OF GEOMETRIC AND MATERIAL CHARACTERISTICS ON THE BEHAVIOR OF REINFORCED-CONCRETE BEAM-COLUMN CONNECTIONS}

VANDANA R. K. ${ }^{1, *}$, BINDHU K. R. ${ }^{2}$

${ }^{1}$ Research Scholar, Department of Civil Engineering, College of Engineering, Trivandrum, India

${ }^{2}$ Associate Professor, Department of Civil Engineering, College of Engineering, Trivandrum, India

*Department of Civil Engineering, College of Engineering, Trivandrum 695 016, India

Tel: (+91) 940060 6576; email: vandana_ranadive@yahoo.co.in; vandana.ranadive@cet.ac.in 


\begin{abstract}
The design of reinforced-concrete moment-resisting frames and hence beam-column connections is of great importance in earthquake-prone areas. Beam-column joints, which should be sufficiently strong to resist and sustain lateral loads, are designed on the basis of the strong-column weak-beam concept so that they undergo ductile failure. The present study describes the cyclic loading performance of six interior beam-column connection specimens designed to be seismic-resistant with varying aspect ratios, concrete compressive strengths, and beam bar yield strengths. Results indicate that joint ductility and energy dissipation capacity can be enhanced by maintaining a unit aspect ratio. Moreover, joint shear strength can be improved significantly by increasing concrete compressive strength. Beam bar yield strength is observed to influence joint ductility considerably.
\end{abstract}

Key words: cyclic loading, seismic analysis, beam-column connection, ductility, reinforced-concrete structures. 


\section{INTRODUCTION}

Special moment-resisting frames are predominant in regions susceptible to moderate to high seismicity. Postearthquake investigations have indicated that beam-column connection failure in seismically detailed frames is caused by shear strength degradation and insufficient energy dissipation capacity, leading to brittle shear failure of the joints and ultimately resulting in structural collapse. Of particular concern is the inadequate strength, ductility, and energy dissipation capacity of these structures for meeting the demands of seismically induced lateral loads.

Beam-column joints have become a focus of attention since 1967, when Hansen and Conner (1967) conducted the first seismic loading test on them. Beam-column joint sub-assemblages play a crucial role in the design of moment-resisting frames as they are the weakest links in the structure. Joints with sufficient shear strength dissipate energy safely without causing any serious structural damage. Such joints fail by developing a ductile beam hinge mechanism. Relevant earthquake-resistant design codes promote joint ductility by incorporating the strong-column weak-beam mechanism. This is expected to ensure the development of plastic hinges in beams at the beam-column interface while all vertical members, including walls and columns, remain elastic in order to provide maximum energy dissipation during an earthquake (Paulay and Priestley 1992; Penelis and Kappos 2010). Although earthquake-resistant structural design codes specify ductile detailing of beamcolumn connections to ensure this behavior, many cases of joint shear failure have been reported globally. Therefore, parameters influencing joint shear behavior clearly require further evaluation.

Joints fail under seismic loading in three possible ways. In the first category, shear failure occurs in joints without affecting the strength of beams framing the columns. This type of failure is brittle and sudden; it must be avoided at any cost. In the second category, beams yield and fail without affecting column or joint safety. This perfect ductile failure is preferred in moment-resisting frames under seismic loading. In the third category, joint failure occurs as a combination of beam yielding followed by joint shear failure. Studies conducted by Goto and Joh (1996), Shiohara and Kusuhara (2009), and Xing et al. (2013) support widely reported cases of joint failures.

A seminal shear transfer mechanism study by Paulay et al. (1978) found that shear force resistance in a joint core arises from two postulated mechanisms: the strut and truss mechanisms. In the strut mechanism, joint shear is transferred via a diagonal concrete strut that sustains only compression. The truss mechanism considers 
the shear resistance contribution of vertical and horizontal reinforcement inside the joint core. The two mechanisms are superimposed to resist the total joint shear force in the horizontal and vertical directions.

Leon $(1989 ; 1990)$ reported that beam bar anchorage length considerably affects joint energy dissipation capacity. An anchorage length of 28 times the bar diameter was necessary to ensure a weak-girder strong-column mechanism through a severe load history. Studies on the effect of column axial loads on the general behavior of joints have produced contradictory results. Some studies have shown that while increased axial loads are favorable to the energy dissipation capacity of joints with small shear, it results in unfavorable effects such as crushing of concrete in joints with high shear (Pantazopoulou and Bonacci 1992; Fu et al. 2000). In a study conducted by Bakir and Boduroglu (2006), the column axial load was reported to be one of the most influential factors on the bond performance of joints.

The study conducted by Pantazopoulou and Bonacci (1994) explored the mechanics of beam-column joints under lateral loads with the aim of assessing the parametric dependence of joint behavior for the benefit of design. The study considered published experimental information from around the world and results from a number of analytical studies collectively, and a finite element model was developed that reproduced joint behavior in agreement with the above results. It was reported that joint hoops serve to confine joint cores while simultaneously participating in the shear-resisting mechanism of the joint panel. It was also observed that participation of the joint core concrete in the mechanism of shear resistance decreases as the number of joint hoops is increased.

Kitayama et al. (2004) highlighted a joint shear transfer mechanism change caused by bond deterioration along the beam reinforcement. It was observed that the ratio of the column width to the beam bar diameter must be limited as a function of the beam bar strength and concrete strength.

Scaling-related effects have raised concerns over the reliability of testing on reduced-scale model structures. It is recommended that the minimum usable scale factor for testing isolated RC components should be one quarter (Abrams 1987; Lu et al. 1999). Investigations conducted by Abrams (1987) focused exclusively on scale relations for RC beam column joints. The study summarized tests of small-, medium-, and large-scale joints. It was reported that, although there were quantitative differences in behavior for specimens of different scales, the same resistance mechanisms were observed for all specimens. Even at one-twelfth scale, the physical models reflected hysteretic characteristics more similarly than most numerical models used in research and in practice. Since force-deflection behavior was simulated well using specimens constructed at one-quarter or larger scales, the study recommended that the minimum usable scale factor for testing isolated reinforced 
concrete components in flexure be one quarter. This conclusion was supported in another study conducted by $\mathrm{Lu}$ et al. (1999) in which the effect of using reinforced concrete scale columns under cyclic action was investigated. The test column specimens were constructed on three scales: 1:2, 1:3, and 1:5.5. All the specimens were reported to behave in a similar manner independent of their scale. In the present study, the specimens were constructed at one-third scale, making them more resistant to scaling-related effects.

The primary obstacle in evaluating joint shear strength is the lack of basic data for appraising the contributions of various factors. It has been reported that concrete compressive strength, transverse reinforcement, and presence of transverse beams or slabs contribute significantly toward improving joint shear strength (Meinheit and Jirsa 1977; Bonacci and Pantazopoulou 1993; Kim and La Fave 2008). The study by Bonacci and Pantazopoulou (1993) reported that transverse beams confine joints by means of their longitudinal reinforcement, which are anchored inside the joints in the transverse direction, as well as by effectively increasing the volume of joint concrete that actively participates in the joint's shear-resisting mechanism.

Studies by Durrani and Wight (1985), Alva et al. (2007), and Kim (2008) found that high concrete strength reduces joint stiffness degradation under lateral loading and is the most significant parameter influencing joint shear strength. However, Meinheit and Jirsa (1977) also showed that joint shear strength degradation occurs regardless of concrete strength.

In contrast, Shiohara (2004) reported that concrete compressive strength is not proportional to joint shear strength. Concrete strength has been widely reported to increase shear strength because of the influence of the bond capacity of longitudinal reinforcement, which in turn is assumed to be proportional to the square root of concrete compressive strength. Shiohara identified the following as major parameters influencing bond capacity: the axial force level of the column due to the confining effect or transverse beams covering a joint, concrete cover thickness, diameter and number of bars, reinforcement yielding, and cyclic loading.

Shiohara (2004) and Mitra and Lowes (2011) reported that aspect ratio, defined as the ratio of beam depth to column depth, has significant influence on joint shear strength. Higher aspect ratios result in lower shear strengths of interior and exterior beam-column joints. Shiohara stressed the need to consider aspect ratio as a critical factor in future code revision.

Reviewing the above-mentioned studies from the viewpoint of interior beam-column joints subjected to cyclic loading reveals several problems. There remain discrepancies in identifying variables that control the joint shear behavior. Systematic variation of every parameter affecting shear strength is beyond the scope of any realistic experimental study. However, selecting certain parameters and systematically varying them can provide 
important insights into joint shear behavior. In the case of interior joints confined in both directions by orthogonal beams, it was reported that the concrete compressive strength was significant only if the joint developed a diagonal strut before failure. It was also reported that it was considerably easier to deteriorate the bonds of longitudinal bars, thereby controlling the response (Pantazopoulou and Bonacci 1994). In interior joints without transverse beams, these effects were not explicitly observed, making this an interesting observation to explore further.

The effect of aspect ratio on joint shear strength has not yet been explored in detail. Shiohara's (2004) suggestion that aspect ratio influences joint shear strength requires experimental investigation, as predicting this effect is critical compared to the other selected parameters. Various tests have provided contradictory views on the effect of concrete compressive strength on joint shear behavior; however, its effect on the ductile behavior of joints has not been investigated thoroughly. Few studies have examined beam bar yield strength effects on joint shear behavior. Therefore, this influence on general joint seismic behavior must be assessed quantitatively. Accordingly, the present experimental study is undertaken to investigate joint aspect ratio, concrete compressive strength, and beam bar yield strength effects on the behavior of seismically detailed interior beam-column joints.

The present study is devoted to experimentally investigating the influence of various parameters on the behavior of joints under cyclic lateral loading. In this study, interior beam-column joints are investigated through test results with the intention of addressing conflicting views of the role of parameters, concrete compressive strength, joint aspect ratio, and beam bar yield strength.

\section{EXPERIMENTAL}

As per IS 13920 (1993), six seismically detailed interior beam-column joint specimens with a height of $1.3 \mathrm{~m}$ and width of $1.5 \mathrm{~m}$ were cast and tested. The mix design was conducted as per IS 10262 (2009). Figure 1 shows the detailing pattern and dimensions of the specimens, which were classified into three groups according to the variables. The same specimen $\mathrm{X} 1$ (control specimen) was included as a standard specimen in all the groups to facilitate comparison with other specimens. It was cast using concrete grade M30 with an aspect ratio of 1. High-yield-strength deformed (HYSD) bars with yield strengths of $500 \mathrm{MPa}$ were used as longitudinal bars in columns and beams. The aspect ratio was selected as the variable in group 1; subsequently, specimens X2 and X3 were designed with aspect ratios of 0.67 and 1.33, respectively. The concrete grade and beam bar yield strength of the specimens were M30 and $500 \mathrm{MPa}$, respectively. The group 2 specimens, i.e., X4 and X5, were designed with variable compressive strengths of M25 and M35, respectively; these specimens had an aspect ratio of unity and beam bar yield strength of $500 \mathrm{MPa}$. The beam bar yield strength was selected as the variable in 
group 3. Thus, specimen X6 consisted of HYSD bars having yield strength of $415 \mathrm{MPa}$ as the beam longitudinal bars. The concrete grade and aspect ratio of specimen X6 were M30 and unity, respectively. Columns in all specimens were reinforced with eight HYSD bars with diameters of $6 \mathrm{~mm}$ and yield strengths of $500 \mathrm{MPa}$ equally distributed along the two longer sides as shown in Fig. 1. The beams were provided with five bars with diameters of $6 \mathrm{~mm}$, i.e., three at the top and two at the bottom. Further, 6-mm hoops were used as transverse reinforcements in both beams and columns. Specimen dimensions and reinforcement details are summarized in Table 1.

\subsection{Materials used}

Ordinary Portland cement (53 grade), M-sand passing through a 4.75-mm IS sieve (fineness modulus, 2.5; specific gravity, 2.5), and crushed stone of maximum size $12 \mathrm{~mm}$ (specific gravity, 2.76) and size $6 \mathrm{~mm}$ (specific gravity, 2.74) were used for this investigation. Electrical resistance strain gauges were fixed on the beam longitudinal bars at the beam-column interface to measure the reinforcement strain during testing.

2.2 Test procedure and instrumentation

Specimens were tested upright in a steel loading frame (capacity, $200 \mathrm{t}$ ). An axial compressive load of $10 \%$ of the axial capacity of the column was applied to the column by means of a hydraulic jack (capacity, $30 \mathrm{t}$ ). The bottom of the column of the beam-column connection was pinned to a strong floor. Beam ends were subjected to quasi-static cyclic loading performed in the displacement control mode. The test setup is shown in Fig. 2. The beams in the beam-column connections were loaded up to a certain magnitude of displacement and then unloaded in the opposite direction and reloaded in order to obtain a full cycle of reverse loading. Each loading cycle was repeated twice; after each cycle, the displacement magnitude was increased. The process was continued until the specimen reached its maximum capacity. Thereafter, loading was applied without repeating the loading cycle until failure. Figure 3 shows the cyclic loading history. In each loading stage, deflections at the beam tips were measured using two linear variable differential transformers (LVDTs) with a precision of 0.01 $\mathrm{mm}$ and gauge length of $200 \mathrm{~mm}$. Beam reinforcement strain was measured using strain gauges installed in each beam-column connection. Strain, deflection, and load cell readings were recorded using a data acquisition system (National Instruments, DAQ SCXI series).

\section{TEST BEHAVIOR}

Specimens' general behavior was identified on the basis of their hysteresis responses, visible crack patterns, failure modes, stiffness behavior, and reinforcement strains.

\subsection{Crack patterns}


Observed crack patterns are shown in Fig. 4. In specimen X1, the first crack was observed at the beamcolumn junction. As the rate of loading increased, initial cracks widened and additional cracks were formed in the beam and joint panel. Specimen X1 exhibited a beam-joint failure mode, i.e., the specimen underwent beam yielding followed by joint shear failure. In specimen X2, the first crack was observed in the beam at the beamcolumn interface. As the loading rate increased, more cracks developed in the beam than in the joint region. Cracks at the beam-column interface widened; finally, the specimen underwent beam failure rather quickly. Cracks observed for specimens X3 and X4 were initially similar. Initial cracks developed in the joint panel in both specimens. In X4, most cracks were spread across the joint region, with some in column members and a few in beam members; a joint shear failure mode was observed. In X3, there were more cracks in the beam than in the joint region. Cracks spread across the joint and beam regions, indicating shear stress distributions over joint and frame members; finally, the specimen underwent joint shear failure. In specimens X5 and X6, the first crack was observed in the beam-column interface. Further increased loading resulted not only in additional crack development in beams and joint panels, but also in propagation of initial cracks. Cracks widened faster in X5 than in X6 as the rate of loading increased. Most cracks were observed in beam portions near the joint; no column cracks were visible. Finally, the two specimens failed in the preferred ductile beam failure mode as a result of beam flexural yielding.

3.2. Mode of failure

Specimen X1 was selected to compare the three specimen groups with varying parameters. In the first group, where the aspect ratio was varied, three different failure modes were observed. The failure mode of specimen X1 with a unit aspect ratio was a combination of beam flexural failure and joint shear failure (BJF). The preferred case of beam flexural failure (BF) was observed in specimen X2 with an aspect ratio of 0.67. Although the specimen exhibited beam failure, it was rapid. Specimen X3 with an aspect ratio of 1.33 underwent joint shear failure (JF). In the second group of specimens (X1, X4, and X5), where concrete compressive strength was varied, different failure modes were observed. Specimen X4, with the lowest compressive strength, underwent joint shear failure, whereas specimen X5, with the highest compressive strength, underwent beam flexural yielding. This proves the advantage of variable concrete strength in altering the failure mode from shear failure to beam failure. In the third group of specimens (X1 and X6), where beam bar yield strength was varied, two failure modes were observed. Specimen X6 failed in the beam failure mode, whereas specimen X1 failed in the beam-joint failure mode.

\subsection{Hysteresis behavior}


Hysteresis responses of joint specimens were recorded throughout the loading cycle, as shown in Fig. 5(a)(f). The thick line at the center of the graph represents the initial cycles of loading until the specimens started to yield. The wider loops were obtained after reaching the elastic stage and are shown in double lines for each displacement increment. Each loading cycle was repeated twice; curves may be coincident or separated. Gaps between curves signify sufficient strength after crack occurrence. A single loading cycle was applied when the specimens reached the ultimate strength. Gaps between hysteretic curves, which were obtained after reaching the ultimate load, were found to be wider, indicating strength degradation or specimen failure at higher displacement loading. Hysteresis loop areas represent the energy dissipation capacity of each specimen. For clearer comparison, Fig. 6 shows the hysteresis loop envelopes for all specimens plotted in a single graph.

Group 1 specimens The hysteresis loops of specimen X1 followed a gradual and steady reduction in strength. The specimen carried the load gradually through deformation until failure, as indicated by the wider gaps between the loops. The hysteretic curves indicate that, even after reaching its ultimate strength, the specimen provided sufficient strength for the next loading cycle. Specimen X2 exhibited smaller loops despite the BF failure mode. The closer loops indicate steady but rapid reduction in strength until failure. The beam failure and rapid strength reduction indicate good specimen shear strength but poor ductility and low energy dissipation capacity. This may be attributed to the aspect ratio's influence on joint behavior. A lower value of the aspect ratio ( 0.67 in $\mathrm{X} 2)$ promoted a safe shear strength value, but failed to promote ductile beam behavior. As a result, beam failure occurred at the beam-column interface with the joint panel remaining intact as if the beam underwent shear failure. For specimen X3, the curves are not close together for each displacement over two loading cycles, indicating joint shear failure under increasing load.

Group 2 specimens The hysteresis curves of specimen X4 were very similar to those of specimen X3. A wider vertical gap between adjacent loops indicated faster reduction in strength with increasing load. The loops indicated that, after reaching the ultimate load, the frame lost strength very rapidly. The hysteretic loops of specimen X5 showed a steady and gradual increase in strength until attaining the ultimate load followed by a gradual reduction in strength until failure. The ability of specimen X5 to carry the load through deformation was evident from its hysteretic loops. The specimen exhibited good strength during loading even after exceeding the ultimate load.

Group 3 specimens

The curves of specimen X6 are similar to those of specimens X1 and X5 but with wider gaps between loops. The ability of these specimens in carrying the load through deformation was most evident. The strength exhibited by specimen X6 at failure was lower than that exhibited by specimen X1, but X6 
sustained the load through a greater displacement than $\mathrm{X} 1$, indicating high ductility and energy dissipation capacity.

The present study summarized tests of six one-third-scale joints. It may be concluded that quantitative differences in behavior for full-size specimens can occur but resistance mechanisms remain the same. There may be differences in the stiffness degradation and bond strength of joints owing to the difference in geometric scales. However, these effects are not sufficiently significant to influence the failure mechanisms or shear resistance of joints (Abrams 1987; Lu et al. 1999).

\section{DISCUSSION OF TEST RESULTS}

4.1. Ultimate strength behavior of test specimens

Group 1 specimens $\quad$ Aspect ratio exerted strong influence on specimen strength. Specimen X1 with a unit aspect ratio reached an ultimate load of $12.75 \mathrm{kN}$ during loading (Table 2). Specimen X2 provided better resistance when the ultimate load was increased by $8 \%$. This difference became more obvious compared with the $10 \%$ reduction in ultimate strength exhibited by specimen X3. The behavior of group 1 specimens highlighted the negative influence of aspect ratio on the specimens' ultimate loads.

Group 2 specimens The ultimate strengths of specimens X4 and X5 were compared with that of specimen $\mathrm{X} 1$. When specimen X1 with concrete grade M30 exhibited an ultimate load of $12.75 \mathrm{kN}$, specimen X4 with concrete grade M25 could sustain only $11.06 \mathrm{kN}$ - a 13\% deficit in capacity. Specimen X5 with concrete grade M35 exhibited a $12 \%$ increase with an ultimate load of $14.27 \mathrm{kN}$. The contribution of concrete compressive strength to ultimate strength is evident from the behavior of the group 2 specimens.

Group 3 specimens $\quad$ In the third group, the ultimate load of specimen X6 was observed to be $13.06 \mathrm{kN}-$ an increase of only $2 \%$ compared to the ultimate strength of specimen X1. The ultimate load values are unreliable in terms of verifying the effects of the beam bar yield strength on joint behavior.

\subsection{Joint shear behavior}

Actual joint shear strengths of the test specimens are listed in Table 2. Aspect ratio and concrete compressive strength exerted a strong influence on joint shear behavior. Since the column is assumed to be strong and the design of the frame concentrates on the beam-hinging mechanism, it is generally sufficient to estimate using only the horizontal joint shear. Joint shear force $V_{j}$ and joint shear stress $\tau_{j}$ were calculated as follows:

$V_{j}=V_{1} \frac{l_{b 1}}{j_{1}}+V_{2} \frac{l_{b 2}}{j_{2}}-V_{c}$ 
$\tau_{j}=\frac{V_{j}}{A_{j}}$

where $V_{1}$ and $V_{2}$ are beam shear, $V_{c}$ is column shear, $l_{b 1}$ and $l_{b 2}$ are distances from the column face to the beam's loading point $(650 \mathrm{~mm}), j_{1}$ and $j_{2}$ are the distances from tensile reinforcement to compressive resultants (assumed to be $127.5 \mathrm{~mm}$ ), and $A_{j}$ is the effective area of the joint.

Group 1 specimens Aspect ratio exerts an important negative effect on joint shear strength. When specimen X1 with a unit aspect ratio exhibited a joint shear strength of $7.23 \mathrm{MPa}$, specimen X2 with an aspect ratio of 0.67 exhibited the highest shear strength of $8.01 \mathrm{MPa}$ and specimen X3 with an aspect ratio of 1.33 exhibited the lowest shear strength of $6.59 \mathrm{MPa}$. Compared to the shear strength of X1, that of X2 increased by around $11 \%$ whereas that of X3 decreased by $9 \%$. Therefore, limiting the aspect ratio to desirable values is of primary importance to the shear strength of a joint.

Group 2 specimens Concrete compressive strength was the key factor in promoting joint shear strength. Specimen X4 (concrete grade M25) exhibited a shear strength of $6.13 \mathrm{MPa}$ - a clear $15 \%$ decrease compared to that of specimen X1 (concrete grade M30). When the compressive strength was increased from M30 to M35, specimen X5 exhibited a 12\% increase in shear strength. Thus, the shear behavior of the group 2 specimens was clarified; moreover, the positive influence of concrete strength on joint shear strength was confirmed.

Group 3 specimens As with ultimate strength, specimen shear strength was not influenced by beam bar yield strength. The observed $2 \%$ increase in the shear strength of specimen X6 was insufficient to verify the effect of the beam bar yield strength on joint shear behavior.

4.3. Displacement ductility

Ductile failure is the preferred failure mode of joints subjected to seismic lateral loads. A structure's ductility is defined as its ability to undergo a large amount of deformation beyond the initial yield deformation while maintaining its strength (Penelis and Kappos 2010; Paulay and Priestley 1992; ACI 352 R02 2002). Ductility is measured in terms of the displacement ductility factor, which is the ratio of the maximum deformation $(\delta \mathrm{u})$ to the deformation at yield ( $\delta \mathrm{y})$ (Shannag et al. 2005; Bindhu and Jaya 2010; Ganesan et al. 2014). Load displacement envelopes are plotted (Fig. 6) and ductility factors calculated accordingly are listed in Table 2 .

Group 1 specimens In this group, specimen X1 exhibited the highest ductility factor of 2.61. Specimen $\mathrm{X} 3$ was the least ductile, with a ductility factor of 1.28. Although specimen X2 followed a beam failure pattern, its ductile behavior was not evident (i.e., it had a low ductility factor of 1.88) because of the brittleness effect on 
beam behavior at the beam-column interface due to its aspect ratio of 0.67 . The ductility factor of specimen $\mathrm{X} 1$ with a unit aspect ratio was 1.4 and 2.04 times greater than those of X2 and X3, respectively. Therefore, it can be theorized that a unit aspect ratio plays a significant role in providing sufficient joint ductility. In seismic zones where ductile behavior is necessary, utmost care should be taken to limit the aspect ratio of joints to unity.

Group 2 specimens Among specimens X1, X4, and X5 with varying concrete compressive strength, maximum and minimum ductility were observed for specimens with the highest and lowest strengths, respectively. A gradual increase in ductility ratios $(1.96,2.61$, and 4.17) was observed for specimens X4, X1, and $\mathrm{X} 5$, respectively, indicating positive influence of concrete compressive strength on ductile joint behavior. The ductility factor of specimen X5 (concrete grade M35) was 1.6 and 2.1 times greater than those of X1 (concrete grade M30) and X4 (concrete grade M25), respectively.

Group 3 specimens In the third group of specimens (X1 and X6), X6 achieved a maximum ductility factor of 4.77 compared to 2.61 for specimen X1. Thus, the ductility factor of X4 was 1.8 times greater than that of X1. Hence, among the three variables considered, beam bar yield strength has the greatest influence on ductile joint behavior. Thus, using beam bars with lower yield strengths can be regarded as a feasible design approach that should be carefully considered in seismic design.

\subsection{Energy dissipation capacity}

Energy dissipation capacity is important in assessing the seismic resistance of a structure. A structure can withstand strong ground waves due to earthquakes only if it possesses sufficient ability to dissipate seismic energy. The area under the load-displacement hysteresis loop represents the dissipated energy during every load cycle (Leon 1989; Shiohara 2004; Mitra and Lowes 2011).

Group 1 specimens $\quad$ Specimen X1 (unit aspect ratio) exhibited the highest energy dissipation capacity of $2.48 \mathrm{kNm}$ among group 1 specimens. Capacity decreased by $36 \%$ in the case of specimen X2 (with an aspect ratio of 0.67$)$. Although a higher aspect ratio implies higher joint shear strength, it does not enhance joint energy dissipation capacity, as is evident from the $41 \%$ reduction in the energy dissipation of specimen X3 (with an aspect ratio of 1.33). The results demonstrate the significance of maintaining a unit aspect ratio for connections to provide sufficient energy dissipation capacity during load reversals.

Group 2 specimens A consistent increase in energy dissipation was observed with increasing concrete compressive strength. Specimen X5 (concrete grade M35) exhibited an increase of around 25\% while specimen X4 (concrete grade M25) exhibited a decrease of 27\% compared to the energy dissipation capacity of specimen X1 (concrete grade M30). 
Group 3 specimens $\quad$ Specimen X6 exhibited the highest energy dissipation capacity because of its enhanced ductile behavior due to reduced beam bar yield strength (415 MPa). Its energy dissipation capacity was $40 \%$ greater than that of specimen X1, where 500-MPa HYSD bars were used as beam bars.

In general, three variables were observed to have a significant influence on the energy dissipation capacity of joint specimens (Figure 7) and should be considered in the seismic design of frames: unit aspect ratio, high compressive strength, and relatively low beam bar yield strength should be prioritized. It has been reported that reducing the aspect ratio by lowering the beam depth and increasing the column depth improves the function of a strong column/weak girder design. However, test results proved that lowering the aspect ratio to below unity is not favorable as it deteriorates the energy dissipation capacity considerably.

\subsection{Stiffness degradation}

The slope of the straight line joining each hysteresis loop peak (load vs. displacement) represents the secant stiffness for that half cycle. The average stiffness obtained for the two half cycles in a hysteretic loop gives the approximate stiffness for that particular cycle ( $\mathrm{Lu}$ et al. 2012). Fig. 8 shows the stiffness degradation curves of the six specimens.

Group 1 specimens Among specimens X1, X2, and X3, X3 exhibited the lowest initial stiffness and the fastest stiffness degradation. Specimens X1 and X2 exhibited relatively higher stiffnesses and lower strength degradation rates. Shear strength reduction and crack propagation decreased stiffness with increasing displacement.

Group 2 specimens Among group 2 specimens, X5 and X4 exhibited the highest and lowest initial stiffnesses, respectively. Specimen X5 (concrete grade M35) exhibited the lowest rate of stiffness degradation compared to specimen X1. Hence, stiffness degradation and initial strength are significantly influenced by concrete strength.

Group 3 specimens Comparing specimens $\mathrm{X} 1$ and $\mathrm{X} 6$ shows that beam bar yield strength does not contribute significantly to stiffness enhancement. The two specimens exhibited approximately equal initial stiffnesses, but stiffness degradation occurred somewhat more rapidly for specimen X6.

Among the three variables considered, concrete strength significantly enhanced specimen stiffness capacity.

\subsection{Reinforcement strain of beam bars}

Beam longitudinal bar strains were measured at the beam-column interface using strain gauges and are plotted against deformation in Fig. 9. The maximum strain readings signify the stage of failure for each 
specimen. As shown by the graph, the higher the strain, the higher the reinforcement yielding throughout the loading history.

Group 1 specimens $\quad$ Specimen $\mathrm{X} 2$, which failed in the beam flexure mode, exhibited the highest reinforcement strain compared to specimens X1 and X3. The strain increased sharply and abruptly when the specimen approached its ultimate displacement. The lowest strain was observed for specimen X3, which underwent shear failure.

Group 2 specimens $\quad$ Consistent strain patterns were observed for specimens X1, X4, and X5 with varying concrete compressive strength. Specimen X5 (a case of BF) exhibited the highest strain, whereas specimen X4 (a case of JF) exhibited the lowest strain. For X1 and X5, strain increased gradually and steadily through a large amount of displacement.

Group 3 specimens $\quad$ Specimen X6, which had beam bars of low yield strength and experienced beam failure, exhibited the highest strain. The attainment of maximum strain was steady and gradual, indicating beam bar yielding via displacement. Among the three variables considered, reinforcement strain was the most significant factor affecting beam bar yield strength.

4.7. Observations on specimen failure modes

Specimen X1 had a design concrete strength of M30 and a unit aspect ratio. These together constitute comparatively good but insufficient joint shear strength for resisting shear failure. As a result, the specimen failed in a combined mode of beam joint failure. Specimen X2 had a design concrete strength of M30, but its aspect ratio was 0.67 . Even though it improved the joint's shear resistance, the strength of the beam was reduced considerably. This led to the sudden failure of beams as if in shear. The failure of specimen X3 was mainly influenced by the high aspect ratio value. This weakened the strong column/weak girder design, and subsequently, the specimen failed in joint shear. The design concrete strength of specimen X4 was M25, and this proved to be the controlling factor in the shear failure mode observed. Specimen X5 was designed for the highest design strength of M35 and had a unit aspect ratio. These together maximized the joint shear strength, and the specimen failed in a ductile beam failure mode. In the case of specimen X6, the favorable factors were the unit aspect ratio, design strength of M30, and longitudinal beam bars with relatively low yield strengths. These three factors together were responsible for the perfect ductile beam failure of the specimen.

\section{CONCLUSIONS}

Results indicate that the aspect ratio of joints has a negative influence on joint shear strength. Ultimate strength, joint shear strength, stiffness, and energy dissipation capacity are greatly influenced by concrete 
compressive strength. The use of steel bars with relatively low yield strengths as beam longitudinal bars could enhance ductility behavior and energy dissipation capacity significantly. The conclusions of this study are listed below:

1) Changing the aspect ratio of joints results in a remarkable response in the behavior of beam-column joint specimens. The specimen with the smallest aspect ratio exhibited the largest joint shear strength and ultimate strength. Further, the aspect ratio could alter the mode of failure of joints from beam-joint failure to beam failure.

2) The specimen with the highest aspect ratio exhibited the lowest shear strength, ultimate strength, ductility, and energy dissipation capacity. Moreover, its mode of failure was not desirable.

3) Specimens with a unit aspect ratio exhibited better ductility and higher energy dissipation capacity than those with the minimum aspect ratio.

4) Energy dissipation capacities degraded considerably when aspect ratios were 0.67 or 1.33 . Hence, in seismic zones, aspect ratios for beam-column joints of unity are preferable to higher or lower values.

5) Reducing concrete compressive strength below the grade of M30 should be avoided, as it severely degrades joint shear strength, ultimate strength, and stiffness. Moreover, it could result in joints with a brittle shear failure mode.

6) Increasing concrete compressive strength above grade (M35) is highly recommended, as this can result in a perfect ductile beam-joint failure mode.

7) The most favorable responses in terms of joint shear strength, ultimate strength, energy dissipation, and ductility corresponded to the highest concrete compressive strengths.

8) The use of Fe 415 steel for beam longitudinal reinforcement does not enhance ultimate strength or joint shear strength significantly.

9) Beam bar yield strength showed a greater influence on ductility and energy dissipation capacity of beam-column joints than concrete compressive strength.

10) The use of Fe 415 steel bars rather than other high-yield-strength bars is highly recommended for longitudinal reinforcement of beams in frames in seismically vulnerable zones.

\section{LIMITATIONS AND FUTURE RESEARCH}

In the present study, the behavior of beam-column joints without transverse beams or slabs under cyclic lateral loading was investigated. Eccentricity of beams is another aspect that was ignored in the present study. Most joints are vulnerable to eccentric effects in beams in practical situations. The insights gained from the 
present investigation can form a good foundation for future research considering aspects such as the effects of eccentric beams and the presence of transverse beams/slabs on the seismic resistance of joints.

\section{Acknowledgements}

The authors wish to gratefully acknowledge the Government of Kerala (Quality Improvement Programme) for financially supporting this study and Editage (www.editage.com) for providing language editing services. 


\section{References}

Abrams, D.P. 1987. Scale relations for reinforced concrete beam-column joints. ACI Structural Journal, 84(6): $502-512$

ACI 352-R02, Recommendations for design of beam column connections in monolithic reinforced concrete structures. Farmington Hills, American Concrete Institute, 2002.

Alva, G.M.S., De Cresce El Debs, A.L.H., and El Debs, M.K. 2007. An experimental study on cyclic behaviour of reinforced concrete connections. Canadian Journal of Civil Engineering, 34(4): 565-575.doi: 10.1139/106-164.

Bakir, P.G., and Boduroglu, H.M. 2006. Nonlinear analysis of beam column joints using softened truss model. Mechanics Research Communications, 33:134-147.

Bindhu, K.R., Jaya, K.P., and Manicka Selvam, V. 2008. Behaviour of exterior beam column joints with nonconventional reinforcement detailing. Journal of Structural Engineering and Mechanics, 30(6): 733-76. doi: $10.12989 /$ sem.2008.30.6.733

Bonacci, J., and Pantazopoulou, S. 1993. Parametric investigation of joint mechanics. ACI Structural Journal, 90(1): 61-71.

Durrani, A.J., and Wight, J.K. 1985. Behaviour of interior beam to column connections under earthquake type loading. ACI Journal, 82: 343-349.

Fu, J., Chen, T., Wang, Z., and Bai, S. 2000. Effect of axial load ratio on seismic behaviour of interior beam column joints. Proceedings of the 12th World Conference on Earthquake Engineering, New Zealand, 30th January-4 February 2000. p.2707.

Ganesan, N., Indira, P.V., and Sabeena, M.V. 2014. Behaviour of hybrid fibre reinforced concrete beam column joints under reverse cyclic loads. Materials and Design, 54: 686-693. doi:10.1016/j.matdes.2013.08.076.

Goto, Y., and Joh, O. 1996. An experimental study on shear failure mechanism of reinforced concrete interior beam column joints. Proceedings of the 11th World Conference on Earthquake Engineering, Mexico, 23-28 June 1996. Paper 1194.

Hanson, N.W., and Conner, H.W. 1967. Seismic resistance of reinforced concrete beam column joints. ASCE Journal of Structural Division, 93(5): 533-560.

IS 13920: 1993(reaffirmed 2002). Ductile Detailing of reinforced Concrete Structures subjected to Seismic Forces. Bureau of Indian Standards, New Delhi, India, 2002. 
IS 10262: 2009. Guidelines for concrete mix design proportioning. Bureau of Indian Standards, New Delhi, India, 2009.

IS 1786: 2008. High strength deformed steel bars and wires for concrete reinforcement-Specification. Bureau of Indian Standards, New Delhi, India, 2008.

IS 1599: 1985(reaffirmed 2012). Method for bend test. Bureau of Indian Standards, New Delhi, India, 2012.

Kim, J., and LaFave, J.M. 2008. Probabilistic joint shear strength models for design of RC beam column connections. ACI Structural Journal, 105(6): 770-780.

Kitayama, K., Otani, S., and Aoyama, H. 1987. Earthquake resistant design criteria for reinforced concrete interior beam column joints. Proceedings of the Pacific Conference on Earthquake Engineering, New Zealand, 58 August 1987. Vol.1. pp.315-326.

Leon, R.T. 1989. Interior joints with variable anchorage lengths. Journal of Structural Engineering, 115(9): $2261-2275$.

Leon, R.T. 1990. Shear strength and hysteresis behaviour of interior beam column joints. ACI Structural Journal, 87(1): 3-11.

Lu, X., Urukap, T.H., Li, S., and Lin, F. 2012. Seismic behaviour of interior RC beam column joints with additional bars under cyclic loading. Earthquake and Structures, 3(1): 37-57.

Lu, Y., Vintzileou, E., Zhang, G.F., and Tassios, T.P. 1999. Reinforced concrete scaled columns under cyclic actions. Soil Dynamics and Earthquake Engineering, 18: 151-167.

Meinheit, D.F., and Jirsa, J.O. 1977. The shear strength of reinforced concrete beam column joints. CESRL Report 77-1, The University of Texas, Austin.

Mitra, N.S., and Lowes, L.N. 2011. Probabilistic model for failure initiation of reinforced concrete interior beam column connections subjected to seismic loading. Engineering Structures, 33: 154-162. doi:10.1016/j.engstruct.2010.09.029.

Pantazopoulou, S., and Bonacci, J. 1992. Consideration of questions about beam column joints. ACI Structural Journal, 89(1): 27-36.

Pantazopoulou, S., and Bonacci, J. 1994. On earthquake-resistant reinforced concrete frame connections. Canadian Journal of Civil Engineering, 21(2): 307-328, doi: 10.1139/194-032

Paulay, T., and Priestley, M.J.N. 1992. Seismic Design of Reinforced Concrete and Masonry Buildings. John Wiley \& Sons, New York. 
Paulay, T., Park, R., and Priestley, M.J.N. 1978. Reinforced concrete beam column joints under seismic action. Journal of American Concrete Institute, 75(11): 585-593.

Penelis, G.G., and Kappos, A.J. 2010. Earthquake Resistant Concrete Structures. Taylor \& Francis Group, Oxon. Shannag, M.J., Abu-Dyya, N., and Abu-Farsakh, G. 2005. Lateral load response of high performance fibre reinforced concrete beam column joints. Construction and Building Materials, 19: 500-508.

Shiohara, H. 2004. Quadruple flexural resistance in RC beam column joints. Proceedings of the 13th World Conference on Earthquake Engineering, Canada, 1-6 August 2004. Paper 491.

Shiohara, H., and Kusuhara, F. 2009. Comprehensive series of tests on seismic performance of reinforced concrete beam column joints. Proceedings of the 3rd International Conference on Advances in Experimental Structural engineering, San-Francisco, 15-16 October 2009.

Xing, G.H., Wu, T., Niu, D.T., and Liu, X. 2013. Seismic behaviour of reinforced concrete interior beam column joints with beams of different depths. Earthquakes and Structures, 4(4): 1-000.

\section{FIGURE CAPTIONS}

Fig. 1. Detailing and dimensions of specimens

Fig. $2 . \quad$ Test setup

Fig. 3. Cyclic loading history

Fig. 4. Crack patterns of test specimens

Fig. 5 Hysteresis loops of test specimens

Fig. $6 . \quad$ Load vs. displacement envelopes of test specimens

Fig. $7 . \quad$ Cumulative energy dissipation

Fig. 8. Stiffness degradation curves of test specimens

Fig. $9 . \quad$ Beam reinforcement strain curves of test specimens 
Table 1. Geometric and material characteristics of specimens

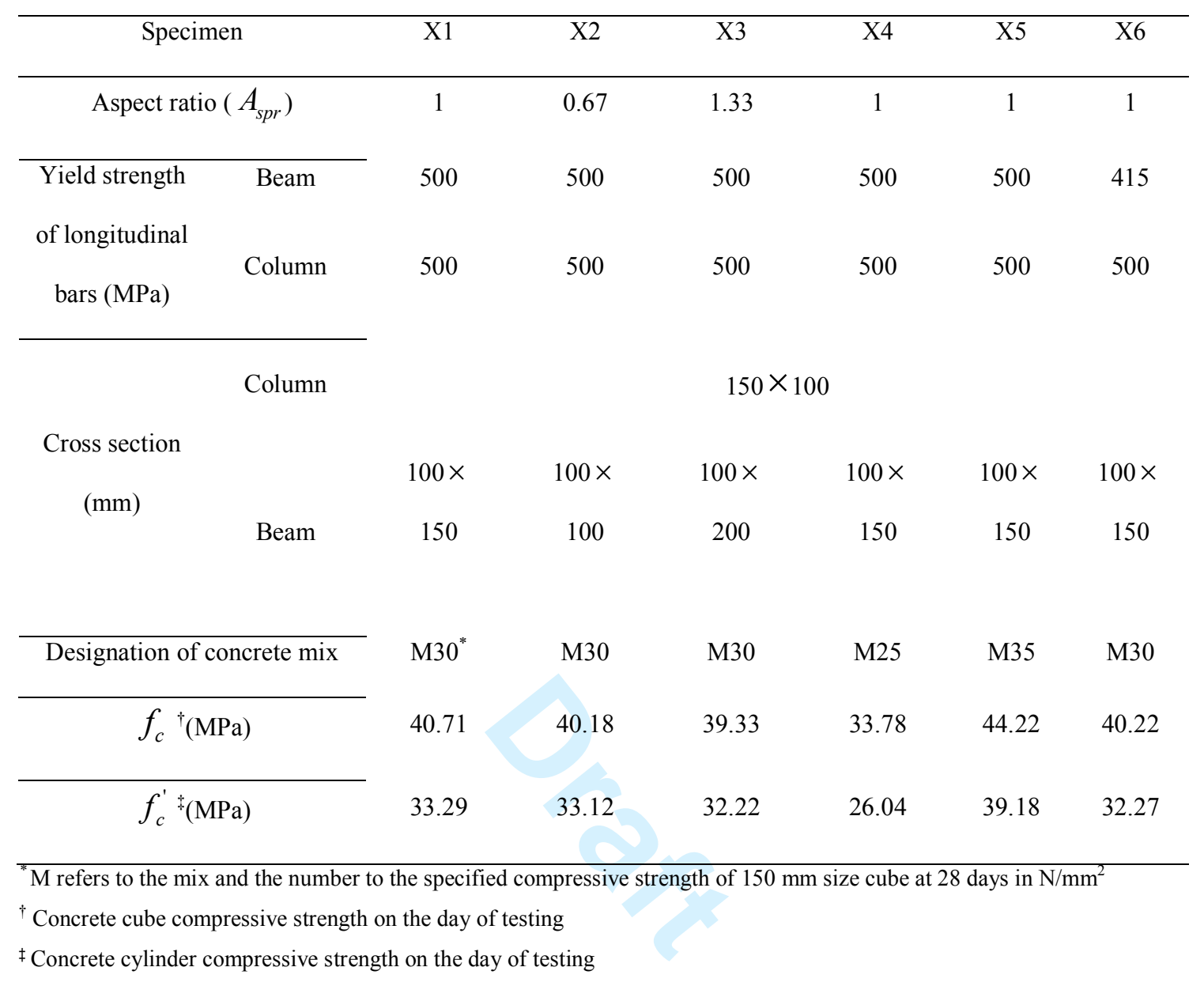


Table 2. Test results

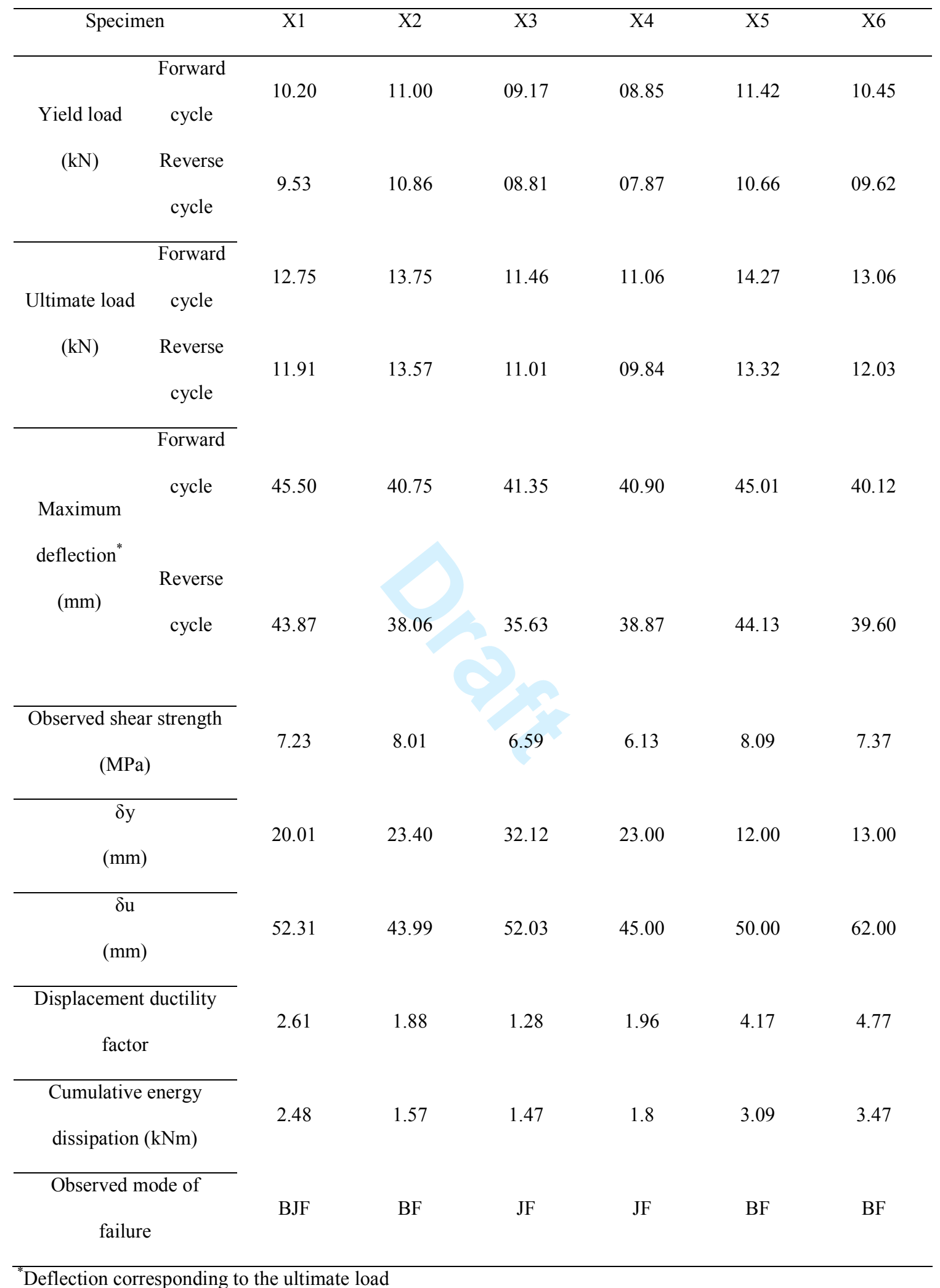




\section{Appendix 1. Longitudinal reinforcement strength}

Table A1 summarizes the tested strength of bars used as longitudinal reinforcements in the test specimens. Three bars from each sample of 10 bars were tested, and the average values are included in the table. The bending test was performed in accordance with the requirements of IS 1599 (2012) and IS 1786 (2008). The reinforcing steel bar, when cold, was doubled over the mandrel by continuous pressure until the sides were parallel. The specimen was considered to have passed the test if there were no ruptures or cracks visible to a person with normal vision along the bent portion.

Table A1. Summary of reinforcing steel bar strengths

\begin{tabular}{lllllll}
\hline $\begin{array}{l}\text { High-yield- } \\
\text { strength }\end{array}$ & Specified & Actual yield & Ultimate tensile & UTS/YS & Modulus of & Bending \\
deformed bars & strength & strength (YS) & strength (UTS) & elasticity & Strength \\
& $(\mathrm{MPa})$ & $(\mathrm{MPa})$ & & & \\
& 500 & 514.6 & 617.4 & 1.20 & $1.998 \times 10^{5}$ & 620 \\
\hline $6 \mathrm{~mm}$ & 415 & 421.8 & 515.7 & 1.22 & $1.89 \times 10^{5}$ & 520 \\
\end{tabular}




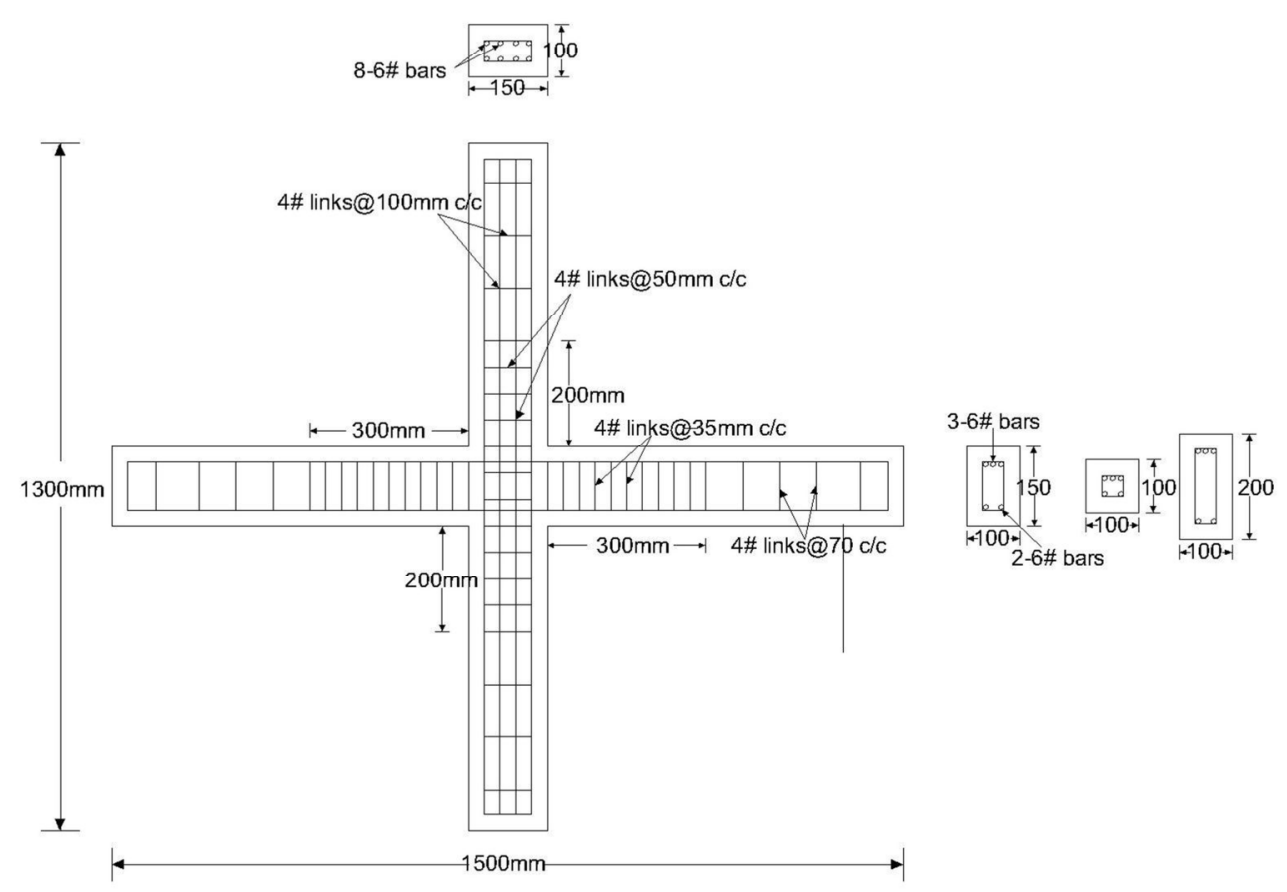

$135 \times 108 \mathrm{~mm}(300 \times 300 \mathrm{DPI})$ 


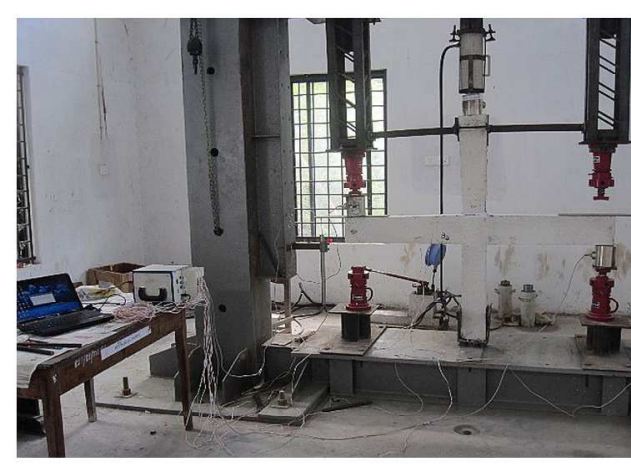

(a) Test setup

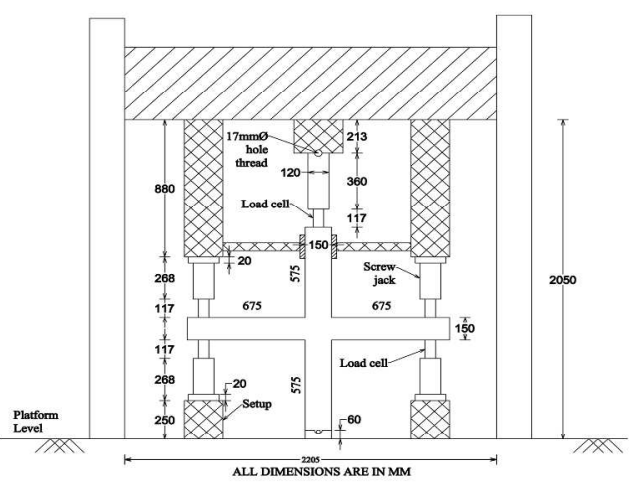

(b) Schematic Diagram

$284 \times 124 \mathrm{~mm}(300 \times 300$ DPI $)$ 


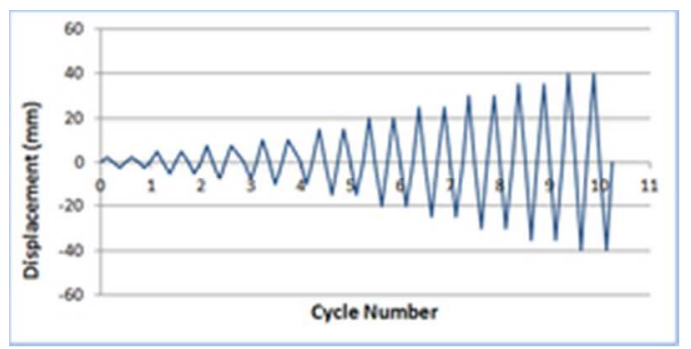

$21 \times 10 \mathrm{~mm}(300 \times 300 \mathrm{DPI})$ 



$149 \times 170 \mathrm{~mm}(300 \times 300 \mathrm{DPI})$ 


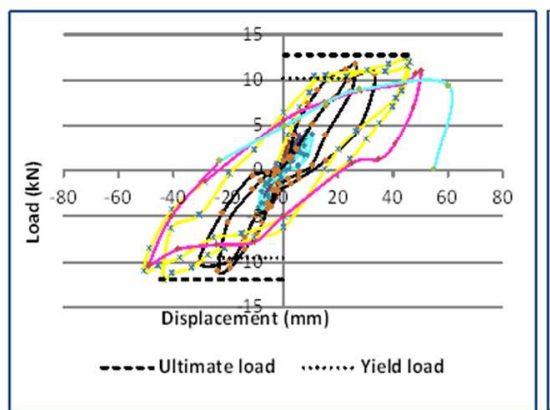

Specimen X1

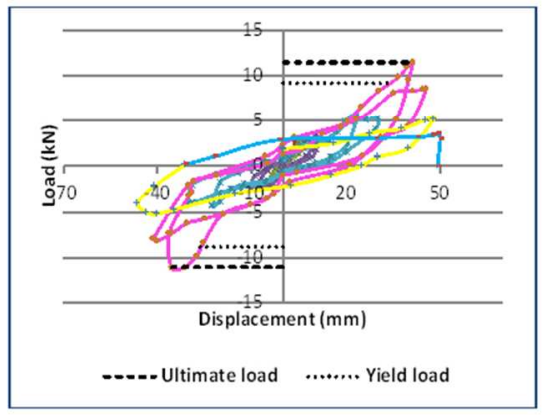

Specimen X3

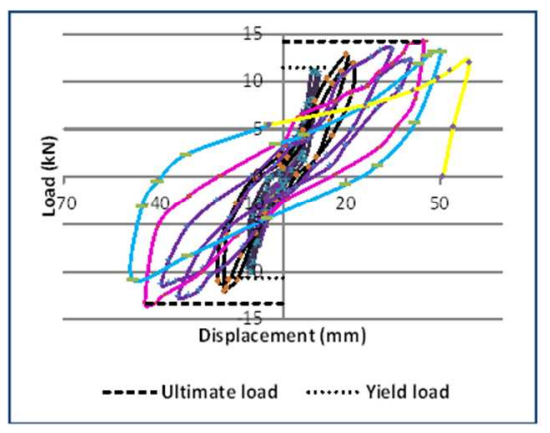

Specimen X5

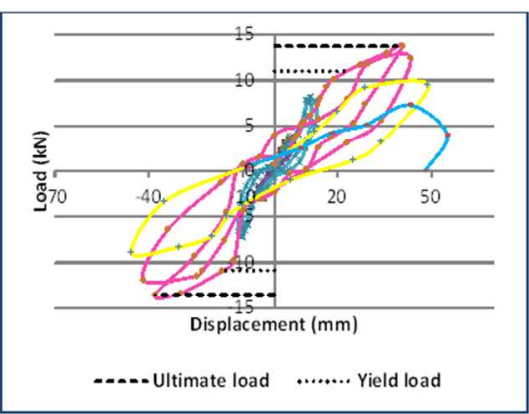

Specimen $\mathbf{X} 2$

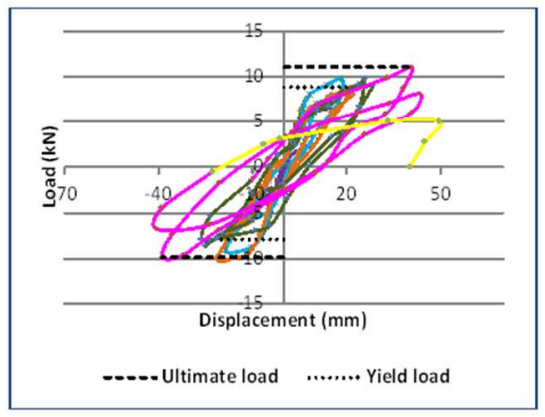

Specimen X4

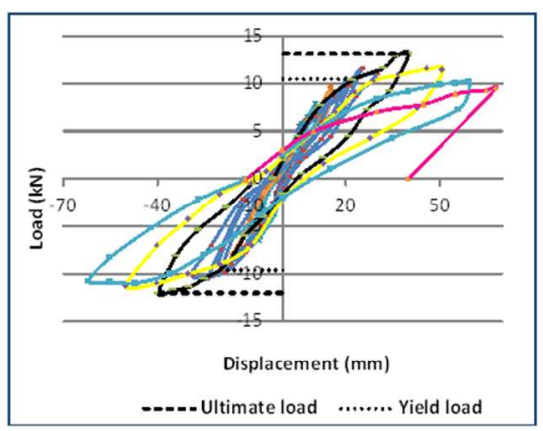

Specimen X6

$221 \times 311 \mathrm{~mm}(96 \times 96$ DPI) 


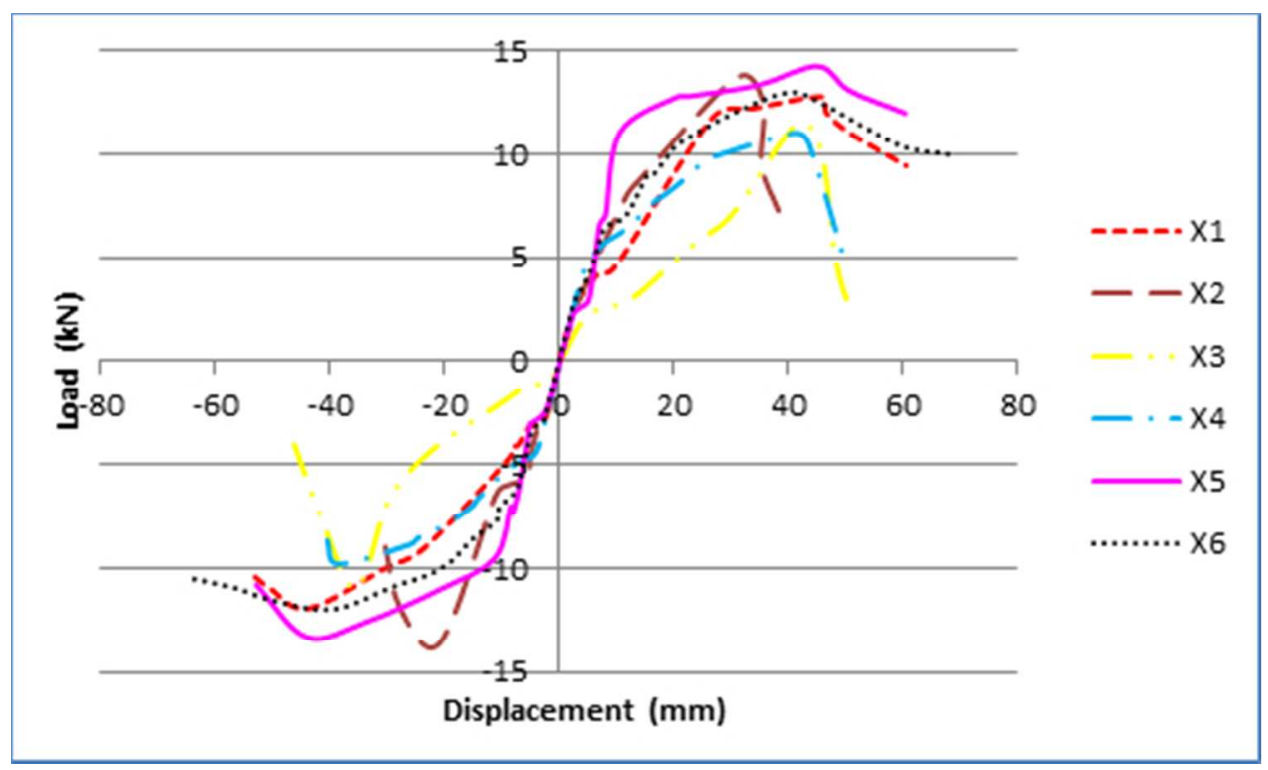

$40 \times 24 \mathrm{~mm}(300 \times 300$ DPI $)$ 


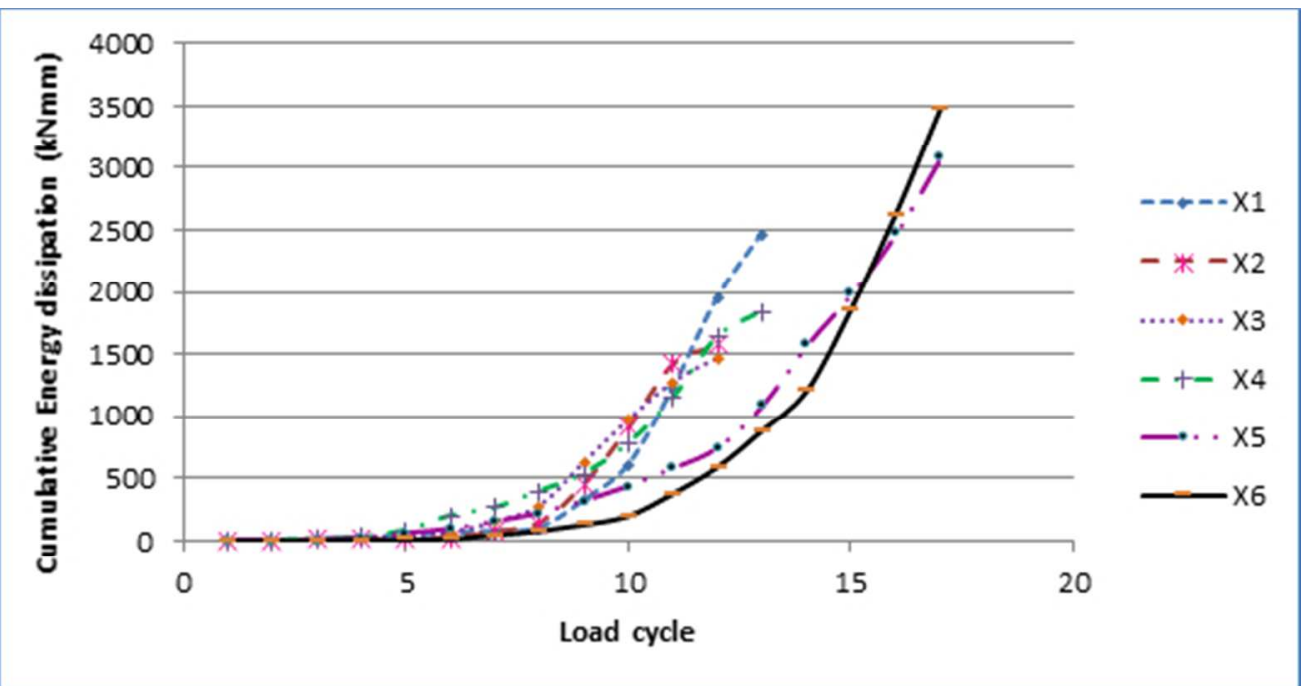

$45 \times 23 \mathrm{~mm}(300 \times 300$ DPI $)$ 


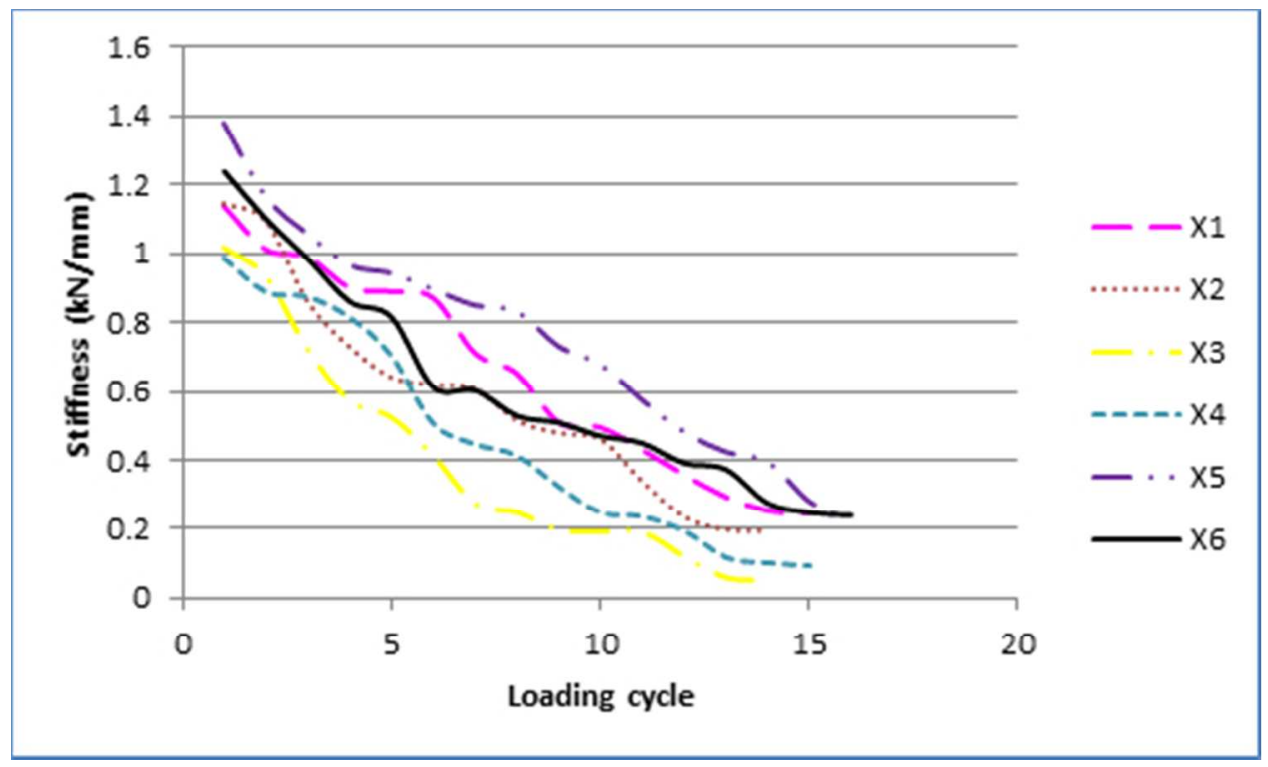

$40 \times 24 \mathrm{~mm}(300 \times 300$ DPI $)$ 


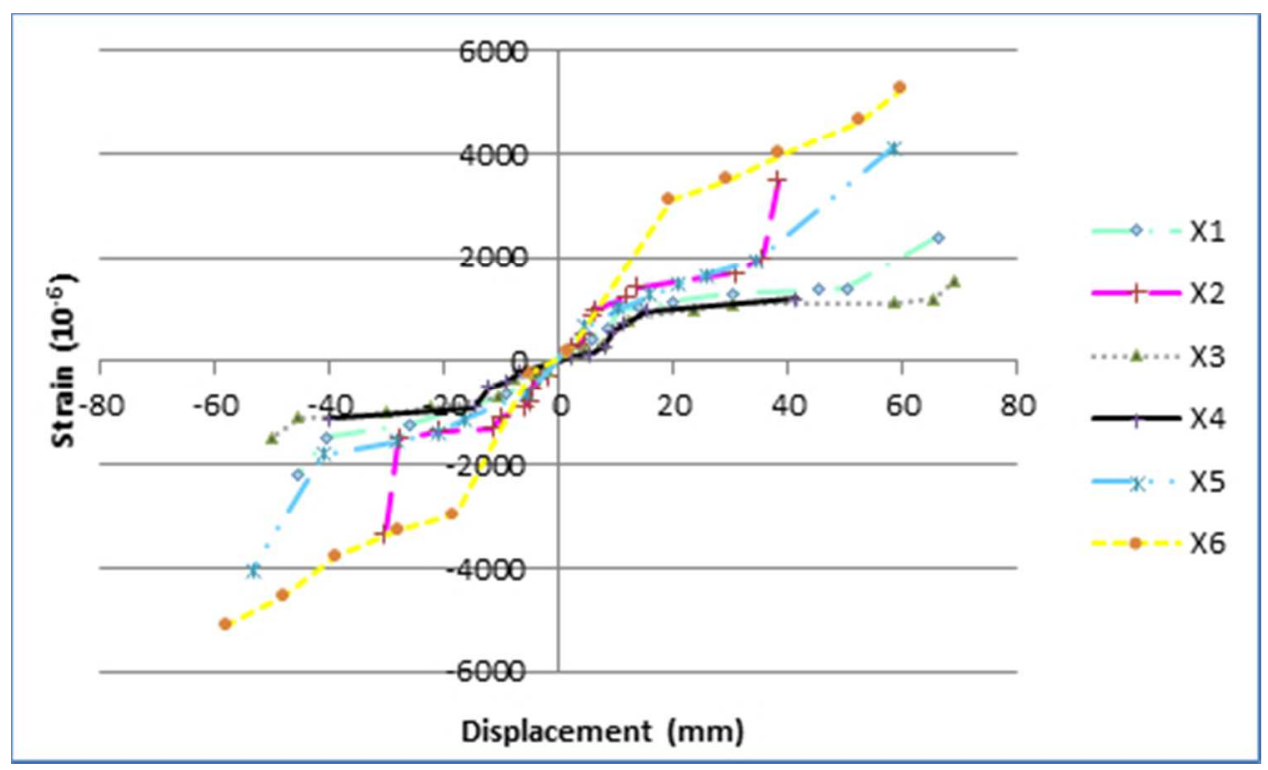

$40 \times 24 \mathrm{~mm}(300 \times 300 \mathrm{DPI})$ 